\title{
Hydroxypropylcellulose Controlled Release Tablet Matrix Prepared by Wet Granulation: Effect of Powder Properties and Polymer Composition
}

\author{
Antonio Zenon Antunes Teixeira* \\ Instituto de Ciências Exatas e da Terra; Departamento de Química; Universidade Federal do Mato Grosso; Av. \\ Fernando Correia s/n; 78060-900; Cuiabá - MT - Brasil
}

\begin{abstract}
The aim of this study was to attain 100\% drug release of caffeine after 24 h from hydroxypropylcellulose (HPC) tablet matrices and to investigate the effect of co-excipient. Physical properties of the powders were evaluated and suggested for a wet granulation process. The tablet containing caffeine was formulated by different weight ratios of hydrophilic polymers. The results of polymer evaluation confirmed that the increase of HPC level with the same drug content significantly decreased the rate of drug release. The presence of co-polymer excipients carboxymethylcellulose $(C M C)$ and polyvinylpyrrolidone $(P V P)$ in the tablet matrix was also investigated. The release rate was also controlled by low levels of CMC $(<10 \%)$ while PVP did not show any considerably effect. The best fit release rate $100 \%$ at $24 \mathrm{~h}$ was obtained when $10 \%$ of $\alpha$-lactose monohydrate was added to the formulation.
\end{abstract}

Key Words: Controlled release, Caffeine, Hydroxypropylcellulose (HPC), Polyvinylpyrrolidone (PVP), Carboxymethylcellulose (CMC), Lactose

\section{INTRODUCTION}

A hydrophilic matrix, rate-controlling polymer (Veiga et al., 1988; Colombo, 1993), is commonly used to control the release of oral drugs. It can be used for control release of both water-soluble and insoluble drugs (Sumathi et al., 2002). Since the polymer is the most critical component of a controlled release tablet, which by virtue of its unique physiochemical properties is able to control the rate release, it has gained importance in the pharmaceutical application both as drug encapsulant and drug carrier (Narasimhan et al., 1997). Many studies have reported that the type of excipient and amount used might affect the drug release profile of controlled release tablets to influence the drug bioavailability (Lin et al., 2004). Solubility is one of important factors in designing a controlled release formulation; therefore, water-soluble cellulose ethers are the most commonly used matrix polymers in a formulation. Hydroxypropylcellulose (HPC) is a non-ionic water soluble cellulose ether with a remarkable combination of properties (Aqualon Product Booklet, 2002). HPC is widely used as an excipient in oral solid dosage forms. It acts as disintegrant and binder in granulation (Francis et al., 2003). The aims of this study were to achieve $100 \%$ caffeine drug release at $24 \mathrm{~h}$ from HPC

* Author for correspondence: azteixei@ufmt.br 
tablet matrix and to investigate the effect of coexcipients.

Caffeine is the most widely consumed behaviorally active substance in the world (Fredholm et al., 1999). It is a highly soluble excipient and its most absorption occurs in the stomach. Its absorption from the gastrointestinal tract is rapid and reaches $99 \%$ in humans at about 45 min after ingestion (Marks and Kelly, 1973), the faster the caffeine leaves the stomach, the quicker and the greater the effect. A peak plasma concentration of caffeine occurs 15-120 minutes after oral ingestion (Fredhlom et al., 1999; Arnaud and Welsch, 1982). It is rapidly distributed to the tissue from plasma into the brain by simple diffusion. As its plasma half-life is 3 to 5 hours, if caffeine is administered frequently throughout the day, there can be a compounding effect as it builds up in the body. In order to reduce the frequency of administration and to improve the patient compliance (Huang et al., 2001; Brazel et al., 1994), controlled release of caffeine was designed in HPC tablet matrix.

Carboxymethylcellulose (CMC) and polyvinylpyrrolidone (PVP) were selected as the drug modifiers, and $\alpha$-lactose monohydrate, which is one of most popular excipients (Bolhuis et al., 2004), together with small amount of amorphous lactose, was used as a water soluble diluent.

\section{MATERIALS AND METHODS}

\section{Raw materials}

Caffeine, lot \# 03A0808 was used as an active excipient. Hydroxypropylcellulose (HPC-HXF), lot \# S-1101 and carboxymethylcellulose (CMC), lot \# 04B0910 were used as polymer carriers. Polyvinylpyrrolidone (PVP), lot \# T99B0311 was used as binder. $\alpha$-lactose monohydrate, lot \# 04B0204 as diluent and magnesium stearate, lot \# T99B0211 as lubricant were also introduced in the formulation. All materials were obtained from Toronto Institute Pharmaceutical Technology, Toronto, ON, Canada.

\section{Powder characteristics}

The powders were analyzed for their physical properties including for its solubility, flowability, and size distribution. Caffeine solubility was tested using a $200 \mathrm{mg}$ available dose. This amount was dissolved in $250 \mathrm{ml}$ of $\mathrm{pH} \mathrm{1.5,} \mathrm{5.8,} \mathrm{and} 6.8$ buffers at $37^{\circ} \pm 0.5^{\circ} \mathrm{C}$. The solution was stirred with a magnetic stirrer at low speed. A sample was withdrawn and the concentration was measured by UV absorbance at $272 \mathrm{~nm}$.

The flow property of excipients was measured through Carr's index, [((tapped density-bulk density)/tapped density) x 100]. In this method, the bulk powder was transferred carefully into a 100 $\mathrm{ml}$ graduated cylinder by a scoopula and the powder's volume was recorded. The bulk density was calculated from the weight of the powder divided by the volume of the powder. Three cylinders were tapped 100 times to settle the powder. It continued until a constant value was obtained to measure the tapped density. The procedure was performed three times and its tapped density was calculated as above after tapping. Another way to measure the flowability was measuring the angle of repose. Powders were passed through a funnel which was lifted to allow the material to form a powder heap. The shape of the powder heap was used to determine how well the powders flowed. The formula used was $\tan \theta=$ 2 height/diameter.

Sieve analysis of particle size and its distribution was performed using Rotap model RX 29 serial\# 11488TIPT97001. The test procedures followed the USP Physical Tests <786> on solid particles. A $100 \mathrm{~g}$ of sample was shaken for 5 minutes in the standard sieves in the range of 44 to $1000 \mu \mathrm{m}$. Each sieve along with the retained particles was weighed individually after shaking. The test was completed when the weight on the test sieves did not change by more than $5 \%$ of the previous weight.

\section{Tablet Preparation}

Different tablet formulations were mixed and blended. The mixture was wet granulated and wet screened on a screen of 16 mesh, and dried in a Heidolph precision scientific tray drier at $35^{\circ} \mathrm{C}$. The granules were lubricated with $1 \%$ magnesium stearate and compressed with tableting machine (Pennwalt Stokes). Tablet weights and compression speed were measured and kept constant.

\section{Dissolution Studies}

The release rate from each batch was evaluated in vitro using a dissolution test apparatus Vankel ID\# DSL 008. The samples were immersed in $900 \mathrm{ml}$ distilled water and phosphate buffer at $\mathrm{pH}$ 6.8. The 
temperature was maintained at $37^{\circ} \pm 0.5^{\circ} \mathrm{C}$ with a paddle rotation speed of $75 \mathrm{rpm}$ (USP Apparatus 2). A sample was withdrawn from each of six vessels and analyzed for caffeine by UV absorbance at $274 \mathrm{~nm}$ using an UV-Visible detector. Its average values and standard deviations were used to plot the release profiles.

\section{RESULTS AND DISCUSSION}

\section{Powder Characteristics}

Solubility is important factor influencing the polymers use in a hydrophilic tablet matrix. The test results indicated that caffeine was highly soluble at $\mathrm{pH} 1.5(\mathrm{pH}$ of the biological fluids of stomach), 5.8 and 6.8 (pH of small intestine). The tests at different $\mathrm{pHs}$ were performed to mimic in vivo conditions of drug dissolution and absorption. Flowability tests were performed and summarized in Table 1. HPC HXF and CMC were found to have fair flowabilities, while PVP K90, lactose and caffeine had poor flowabilities.

However, the angle of repose measurements describing the bulk properties became similar. This showed that a single flowability test could not be relied upon. As a general condition, the powders with an angle of repose greater than 50o had unsatisfactory flow properties. The lower the angle the better the flow properties were.

Table 1 - The results of carr's index and angle of repose pharmaceutical materials.

\begin{tabular}{lcccl}
\hline & Carr's index $(\%)$ & & Angle of repose & \\
\hline HPC-HXF & 18.63 & Fair & $27.92^{\circ}$ & Fair \\
CMC & 20.63 & Fair & $29.38^{\circ}$ & Fair \\
PVP-K90 & 29.97 & Poor & $29.28^{\circ}$ & Fair \\
$\alpha$-lactose & 40.43 & Extremely poor & $31.32^{\circ}$ & Fair \\
Caffeine & 29.68 & Poor & $25.35^{\circ}$ & Fair \\
\hline
\end{tabular}

The effect of particle size was evaluated to select the manufacturing process. Figure 1 shows the sieve analysis of polymer excipients. HPC HXF and $\mathrm{CMC}$ were found to have a fine particle size $(100 \%<250 \mu \mathrm{m}$ and $86 \%<250 \mu \mathrm{m}$, respectively). A small particle size has the tendency to agglomerate because of static electric charges. These build up the surface of small particles because they have a much larger specific surface areas than larger particles.

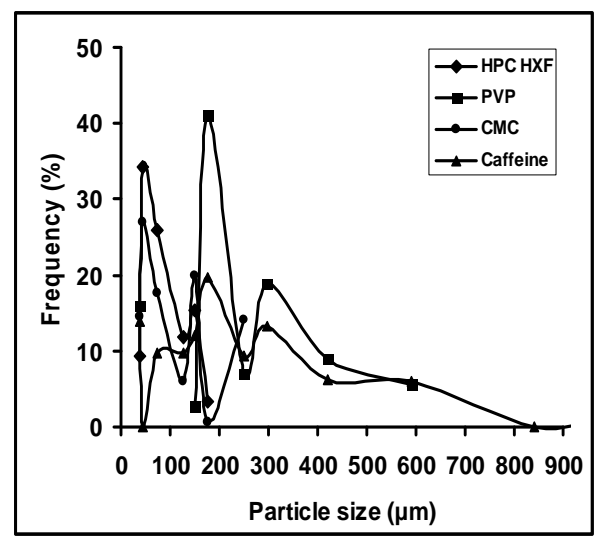

Figure 1 - Particle size and size distribution of materials.

The interactions of the surface-to-surface area may cause small particles to join together and affect their ability to flow. However, PVP and caffeine had a regular particle size and polydispersed particle size distribution. PVP had $60 \%<250 \mu \mathrm{m}$ and $250<40 \%<850 \mu \mathrm{m}$, whereas caffeine had $65 \%<250 \mu \mathrm{m}$ and $250<35 \%<850 \mu \mathrm{m}$. The larger particle size range can form in segregation 
of the particle bed, because it creates spaces through which smaller particles can flow. Thus, it affects the ability to flow.

Poor flowability and large particle size distribution could add to the problems of content uniformity, compressibility and segregation during the manufacturing process. To avoid such problems, wet granulation with a high shear was chosen for the manufacturing process.

\section{The effect of polymers on drug release}

Figure 2 shows how HPC HXF, fine grand particle size polymer, could markedly modify the drug release. The presence of HPC at various levels from 23 to $47 \%$ of soluble caffeine influenced a decrease of the release rate on drug dissolution. The most significant effect was obtained on altering the level of HPC HXF from 33 to $41 \%$, resulting in a decrease at $12 \%$ in drug release. Thus, various concentrations of HPC $(30-40 \%)$ were selected for tablet formulation (Table 2 and Table 3).

Drug solubility seems to exert a greater controlling effect on release rate. CMC is high free flowing water soluble polymer (USP-NF). It is very effective in sustaining the drug release at a low level, $5-10 \%$ of total tablet weight dissolves rapidly in cold water and is physically inert.

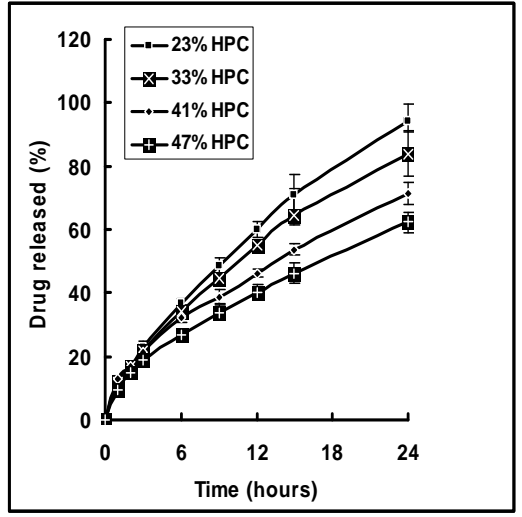

Figure 2 - The effect of different levels of HPC concentration on caffeine drug release profiles. Caffeine loading was kept constant.

Table 2 - Composition (\%) of caffeine formulations with different ratios of selected polymers.

\begin{tabular}{lcccccc}
\hline & F-1 & F-2 & F-3 & F-4 & F-5 & F-6 \\
\hline Caffeine & 50 & 50 & 50 & 50 & 50 & 50 \\
CMC & 12 & 12 & 6 & 6 & 3 & 3 \\
PVP-K90 & 5 & 2.5 & 5 & 2.5 & 5 & 2.5 \\
HPC HXF & 32 & 34.5 & 38 & 40.5 & 41 & 43.5 \\
Release rate after 24 hours & 66.02 & 67.72 & 69.91 & 74.29 & 84.19 & 85.92 \\
\hline
\end{tabular}

Table 3 - HPC tablet matrix (in \%) with addition of various concentrations of $\alpha$-lactose monohydrate.

\begin{tabular}{lccccc}
\hline & F-5.1 & F-5.2 & F-5.3 & F-5.4 & F-5.5 \\
\hline Caffeine & 50 & 50 & 50 & 50 & 50 \\
CMC & 3 & 3 & 3 & 3 & 3 \\
PVP-K90 & 5 & 5 & 5 & 5 & 5 \\
HPC HXF & 39 & 37 & 35 & 33 & 31 \\
Lactose & 2 & 4 & 6 & 8 & 10 \\
Magnesium stearate & 1 & 1 & 1 & 1 & 1 \\
Release rate after 24 hours & 71.06 & 75.90 & 78.35 & 88.56 & 100.16 \\
\hline
\end{tabular}


CMC used in this experiment was 3, 6 and $12 \%$. PVP was chosen as the granulating agent because of its binding and was used at 2.5 and $5 \%$ of tablet weight (Table 2).

The effect of polymers is also described in Figure 3. The changes of drug release rate on HPC matrix were slower with the use of CMC which had a smaller particle size. The increase level of CMC (from $3 \%$ to $6 \%$ ) gave a great effect on the decrease of the drug release (from 80 to $70 \%$ ). On the other hand, CMC did not exert any considerable effect when the level was increased from 6 to $12 \%$. No significant differences of drug release occurred when PVP level was changed from 2.5 to $5 \%$. The release rate was apparently regulated by the presence of $\mathrm{CMC}$.

The composition of CMC : PVP (3\%: $5 \%)$ was able to reach the best profile and closest with the required rate. $\alpha$-lactose monohydrate having large particle size was used to accelerate the drug release. Various concentrations were formulated, and $10 \%$ of lactose was able to give $100 \%$ drug release after $24 \mathrm{~h}$ (Table 3, Fig. 4)

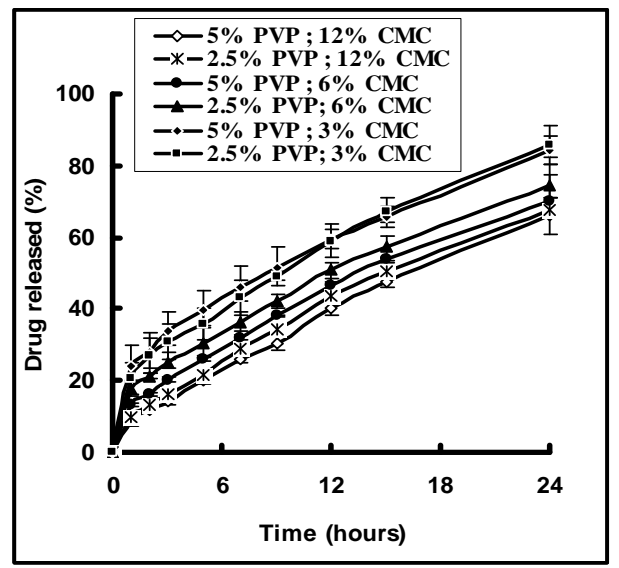

Figure 3 - Effect of PVP and CMC at various levels of drug formulation containing caffeine and HPC HXF.

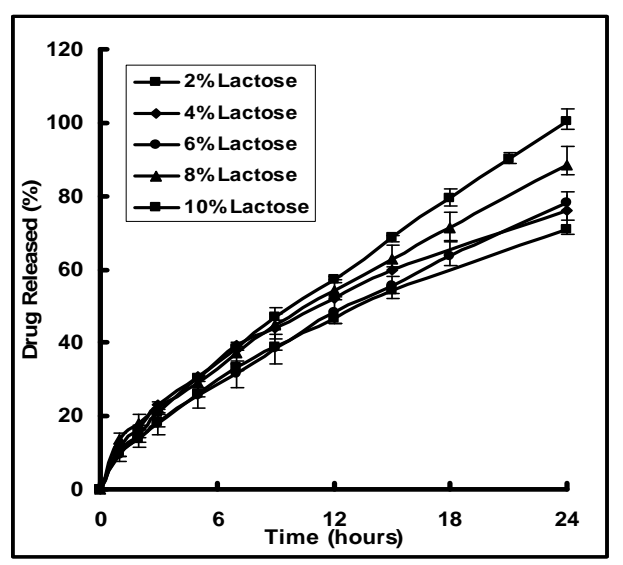

Figure 4 - Impact of $\alpha$-lactose monohydrate on various levels in accelerating drug release. The formulations contain caffeine, HPC HXF with 3\% CMC and 5\% PVP. 


\section{CONCLUSION}

Drug properties and its composition significantly influence the manufacturing technique and drug profile. Different flowabilities and large variation in particle size could cause segregation on the manufacturing process; therefore, wet granulation could be the solution. Drug particle size is also directly proportional to the drug release. A smaller drug particle size decreased the drug release while larger size increased the release rate. A combination of polymers and lactose was able to reach the required drug release.

\section{RESUMO}

O objetivo deste estudo é desenvolver a liberação $100 \%$ da droga cafeína em 24 horas em comprimidos matrizes e investigar o uso de hidroxipropilcelulose (HPC) mais os efeitos de coexcipiente. As propriedades físicas dos pós foram avaliadas assim como seu uso no processo de granulação úmida. $\mathrm{O}$ comprimido contendo a cafeína foi formulado por diferentes relações de peso dos polímeros hidrofílicos. Os resultados da avaliação do polímero confirmaram que o aumento do nível de HPC com o mesmo índice da droga diminuiu significativamente a taxa de liberação da droga. A presença do co-polímero excipiente carboximetilcelulose (CMC) e do polivinilpirrolidona (PVP) na matriz do comprimido foi também investigado. A taxa de liberação foi controlada principalmente por baixos níveis de CMC $(<10 \%)$ enquanto PVP não mostrou efeito diferente considerável. A melhor taxa de liberação de cafeína $100 \%$ em 24 horas foi obtida quando $10 \%$ da lactose monoidrato foi adicionado na formulação.

\section{REFERENCES}

Aqualon Product Booklet 250-2F (2002) Hydroxypropylcellulose physical and chemical properties. Hercules Inc. Wilmington.
Arnaud M.J. and Welsch C. (1982) Theophylline and caffeine metabolism in man. In-Theophylline and Other Methylxanthines ed. Reitbrock N., Woodcock B.G. and Staib A.H. Friedr. Vieweg and Sons, Zurich. pp 135-148,

Bolhuis, G., Kussendrager, K., and Langridge, J. (2004), New Developments in Spray-Dried Lactose. Pharm Tech Excipients and Solid Dosage Forms. pp 26-31.

Brazel, C.S. and Peppas, N.A. (1994), Temperature and $\mathrm{pH}$ sensitive hydrogels for controlled release of antithrombotic agents. Mater. Rest. Soc. Symp. Proc. 331, 211-216.

Colombo, P. (1993), Swelling controlled release in hydrogel matrices for oral route. Adv Drug Del Rev 11, 37-57.

Francis, M.F., Piredda, M. and Winnik, F.M. (2003), Solubilization of poorly water soluble drugs in micelles of hydrophobically modified hydroxypropylcellulose copolymers. J. Contr. Rel 93, 59-68.

Fredholm, B.B., Bättig, K., Holmén, J., Nehlig, A. and Zvartau, E.E (1999), Actions of caffeine in the brain with special reference to factors that contribute to its widespread use. Pharmacol Rev 51(1), 83-133.

Goodhart, W. (1995) Handbook of Pharmaceutical Excipients In-Lactose pp 252-261, American Pharmacist Association, Washington DC.

Huang, Xiao and Brazel, Christopher S. (2001), On the importance and mechanism of burst release in matrixcontrolled drug delivery system. J. Contr. Rel. 73, 121-136.

Lin, S.Y., Li, M.J., Lin, K.H. (2004) Hydrophilic excipients modulate the time lag of time controlled disintegrating press coated tablets. AAPS Pharm. Sci. Tech. 5(4), art. 54.

Marks, V. and Kelly, JF. (1973) Absorption of caffeine from tea, coffee, and coca cola. Lancet 1, 827.

Narasimhan, B. and Peppas, N. (1997), Molecular analysis of drug delivery system controlled by dissolution of the polymer carrier. J. Pharm. Sci. 86, 297-304.

Sumathi, S., Ray, A.R. (2002), Release behaviour of drugs from tamarind seed polysaccharide tablets. $J$. Pharm. Pharmaceu. Sci. 5(1), 12-18.

Veiga, F., Salsa, T., Pina, E. (1988), Oral controlled release dosage forms. II. Glassy polymers in hydrophilic matrices. Drug Dev Ind. Pharm. 24, 1-9. 